\title{
Rural settlement spatial patterns and effects: Road traffic accessibility and geographic factors in Guangdong Province, China
}

\author{
YANG Ren ${ }^{1}$, 'XU Qian², XU Xuanfang ${ }^{1}$, CHEN Yanchun ${ }^{1}$ \\ 1. School of Geography and Planning, Sun Yat-sen University, Guangzhou 510275, China; \\ 2. Guangzhou Institute of Geography, Guangzhou 510070, China
}

\begin{abstract}
Based on land use classification data of remote sensing images, using kernel density, the minimal cumulative resistance model of road traffic accessibility, and a logistic regression model, the characteristics of the spatial pattern and the main factors influencing it were quantitatively examined in Guangdong Province from 1990 to 2013. The framework of the research concerning rural settlement evolution and its effect mechanisms were also discussed and generalized for the future. The results are as follows: (1) The spatial distribution of rural settlements showed spatial directivity of low altitude, low slope, and adjacent to rivers, as well as to villages and towns; thus a special pattern was formed, which was dense on the plains, sparse in mountainous areas, and included two core high density regions of rural settlements in the Chaoshan plain in the east and the Zhanjiang plain tableland region in the west. The spatial distribution of rural settlements was located along the rivers, valleys, and roads with traffic in the mountainous regions surrounding the Pearl River Delta region. (2) In addition to the spatial orientation of the open road, it was important to show that the accessibility of road traffic to the township has had the greatest influence on the spatial distribution of the rural settlements. The connected transport network between towns and villages is significant for rural transformation as a comprehensive increase in township production and service capacity will be the key to optimizing the town-village system in rural areas. (3) Elevation and slope were two basic but influential factors that have affected the distribution, scale, and form of rural settlements. The attributes of the physical geography are the first elements in optimizing village layout and planning spatial reconstruction. (4) In the current Internet and social media era, the reconstruction of market network system orders connects with the global market network system in rural areas. The rural life service circle will be constructed with the township at its core to explore the theory and practice of spatial reconstruction, including its production, life and ecology, and socio-cultural heritage and protection. It will also allow for exploration of the rural settlements' evolution, rural spatial production, rural social networks, group behavior, social autonomy, and social and cultural fields, which will be
\end{abstract}

Received: 2018-01-22 Accepted: 2018-03-26

Foundation: National Natural Science Foundation of China, No.41401190, No.41871177, No.41801088; Science and Technology Program of Guangzhou, China, No.201707010097

Author: Yang Ren (1984-), PhD and Associate Professor, specialized in rural geography and land science.

E-mail: yangren0514@163.com

"Corresponding author: Xu Qian (1984-), PhD, specialized in land science and ecological environment assessment and effects. E-mail: xuqian19840613@163.com 
the core focus of China's rural spatial reconstruction research against a background of globalization.

Keywords: rural settlement; spatial feature recognition; traffic accessibility; rural geography

\section{Introduction}

Rural residential area is the carrier of the spatial distribution of rural populations and is also a geographical space carrier with multi-dimensional functions of agricultural production, farmers' livelihoods, and social succession. The spatial distribution and pattern evolvement of rural residential areas is a concentrated reflection of human adaptation to economic geographic conditions, the natural environment, and its historical development (Hamerow, 2012; Yang et al., 2016). The evolution process, pattern, effect, and mechanism of rural settlements is one of the core contents of rural geography studies (Long et al., 2009; Yang et al., 2015a; Xi et al., 2015; Janečková Molnárová, 2017), as well as an important factor of the study of the rural human-environment relationship system, which is of great significance for the cognitive understanding of the elements, structures, functional recombination, and optimization of the rural regional system (Long 2013; Trukhachev, 2015; Yang et al., 2015b; Liu et al., 2017). With the rapid development of industrialization and urbanization, ultrafast conversions have occurred in the structure of production factors of the rural regional system. Rural economies and societies are undergoing a process of rapid succession and transformation, leading to the spatial reconstruction of rural production, lives, ecology, culture, and politics; rural areas are facing the transformation from the productive to the post-productive (Hai et al., 2013; Wang et al., 2014; Peng, 2015). The space layouts and forms of rural settlements have transformed a great deal, and rural construction and planning have attracted the focus of many subjects such as Geography and Urban-rural Planning. In recent years, under the macroscopic background of globalization and urbanization, research on rural physical space and the reconstruction of social space has become a popular topic in the research field of domestic rural geography (Woods, 2007; Schwarz, 2015). The main focus of the reconstruction of rural material space is the layout optimization of rural settlements, infrastructure planning and construction, constructive protection, spatial integration, and the recombination of villages-towns systems, etc. (Zhou et al., 2012). Research on rural settlement geography is always an important field in rural geographical studies, and studies of rural settlements in the rural geography field mainly focuses on the types of rural settlements (Li and Zhang, 2012), spatial morphological characteristics (Ma et al., 2012), the evolution process (Guo et al., 2012), settlement hollowing (Yang et al., 2015c), influencing factors, and driving mechanisms (Zeng et al., 2011; Yang, 2016). After the Fifth Plenary Session of the 16th Central Committee of the Communist Party of China (CPC), the new rural construction and regulation mode has become a popular research topic, and the research emphasizes the transformation of rural settlements into the direction of the spatial landscape pattern of settlements (Zeng et al., 2011; Ma et al., 2012; Ren et al., 2014), settlement regulation, and spatial optimization (Tang et al., 2014; He et al., 2012; Yang et al., 2016), usually carrying out corresponding research work from the research theme of "phenomenon-problems-countermeasures." Other scholars broke through the traditions and created a new research paradigm from the research theme of "trend-mechanism-regulation," which integrates the theories of geography, economics, sociology, ecology, and other subjects syn- 
thetically, deepening the research of the evolvement mechanism of the settlement system, settlement scale, form, function, culture, and environment (Zhou et al., 2012).

At the theoretical level, Christallerr's central place theory is a theory of comprehensive integration (Arthur and Judith, 1966). At the methodical level, neighborhood buffer analysis (Yin et al., 1995; Tian et al., 2014), spatial superimposed analysis (Fan, 1994), and samples with an analysis of geographic information system (GIS) are usually used to analyze the spatial differential laws of rural settlements (Ma et al., 2012; Li et al., 2014; Tian et al., 2016), and the research methods present a transformation from qualitative to the combination with quantification methods. At the level of the driving mechanism, the analyses mainly focus on the influencing factors of spatial directivity (Yang et al., 2015b), as well as from the three dimensions of the basic factors, new factors, and mutation factors of the evolution of rural settlements to analyze the dynamic mechanism of rural settlements (Zhou et al., 2012).

Economic development and the transformation process of industrial development in rural areas directly drive the spatial reorganization of rural settlements and the spatial reconstruction of social culture. The supply of infrastructure and planning guided by science is vital to the reconstruction of the villages-towns system based on the rural life circle, as well as being the key point of realizing the integration of rural production space and the construction of ecological space. The accessibility of road traffic is an important index to measure the structure of regional transportation networks and regional external contact (Huang et al., 2011; Quinn and Wilks, 2017). The road system is an important channel and spatial carrier of the interactive flows of urban-rural production factors. Previous research on the traffic directivity of the space distribution of rural settlements mainly made use of the proximity of Euclidean distance with statistics and buffer analysis to draw the corresponding conclusions. However, there are many differences in physical structure features between all levels of road systems. For example, highways and rails have the structural nature of a "corridor" in the sense of landscape ecology (Chen et al., 2017). Whether the directivity characteristic of proximity settlements is significant requires further examination. The accessibility of road traffic comprehensively reflects the real condition of the traffic location of a random spatial point. Combining the convenience of road traffic and the radiation influence of neighboring centers, traffic accessibility has a certain fundamental significance to the exploration of the spatial distribution directivity of rural settlements and the theory and practice of the reconstruction of the villages-towns system.

Guangdong Province is on the forefront of opening up the south of China. The Pearl River Delta region is one of the three economic growth poles in China whose urbanization rate is over $80 \%$. At the same time, in the periphery of the Pearl River Delta region exist many underdeveloped mountainous areas, and the difference in socio-economic development between the core area and the peripheral area of the Pearl River Delta is the main problem of uneven regional development in Guangdong. The process of bottom-up rural industrialization in the Pearl River Delta region means that rural settlements and organizational forms are still common, and the confounding features of urban and rural landscapes are prominent. The systematic analyses of the settlements' material spaces, social and cultural spaces, spatial characteristics of ecological space reconstruction, evolution, and influence mechanisms under the diversified differentiated transformation of rural space in Guangdong has great 
significance on the study of fundamental theories. It also has great practice reference value which greatly enriches the research category and content of rural geography in economic developed areas. This study is based on the minimum resistance value of the multilevel road system to the different levels of central places as towns and villages in a $100 \mathrm{~m} \times 100 \mathrm{~m}$ space grid unit position within the scope of the domain of Guangdong. The attributed data of the impact factors controlled by the physical geography, comprehensively integrates buffer analysis and spatial random sampling methods and uses the logistic regression model to quantitatively identify the evolution process of the spatial distribution features of rural settlements and the strength and direction of the main factors of the present situation of the spatial distribution of settlements in Guangdong. Based on previous studies, the content framework of the spatial distribution, evolution, and reconstruction mechanisms of rural settlements against the background of the diversified differentiation of rural regional space has been summarized. This is the research theme of the "spatial evolution process of rural settlements-transition response of multi-dimensional space (form, society, landscape) -reconstruction and transformation of multi-dimensional space-driving mechanism of multiple powers." It is clear that this is the content framework and logical line of research on rural settlement geography.

\section{Materials and methods}

\subsection{Study methods}

\subsubsection{Kernel density analysis}

On a certain scale within an area, in the sense of probability, the density and intensity of spatial distribution patterns of rural settlements can be measured at any point. Kernel density estimation is a common method generally defined as: presume that $\mathrm{X}_{1}, \ldots, \mathrm{X}_{\mathrm{n}}$ are independent identically distributed samples extracted from the totality of the distribution density function $f$, and estimate the value of $\mathrm{f}(\mathrm{x})$ when $f$ at $\mathrm{x}$ point according to the Rosenblatt-Parzen kernel estimation usually is (Liu et al., 2010):

$$
f_{n}(x)=\frac{1}{n h} \sum_{i=1}^{n} k\left(\frac{x-X_{i}}{h}\right)
$$

where $k\left(x-X_{i} / h\right)$ is the kernel function; $h>0$ : for bandwidth; $\mathrm{n}$ : the point number of the distributed rural settlement patches in the settlement study area; and $\left(x-X_{i}\right)$ : the distance between the point to estimate and the event $X_{i}$. In the process of estimating the spatial distribution patterns of rural settlements, we chose the intensity estimate of the scale of land use in rural settlements after the density weighting of rural settlement points. The calculation of a specific model is run on the ArcGIS10.2 software platform.

\subsubsection{Calculation method of traffic accessibility}

This study assumes that the resistance values of roads of an identical type are the same and adds a resistance value that is attributed to each of the roads of various types. According to the relevant traffic laws and regulations as well as the driving speeds of cars on the roads, the resistance value of a state road is set at 3 , a provincial highway is set at 4 , an urban expressway is set at 3 , county roads are set at 6 , roads in villages and towns and other roads are 
set at 8 , and areas with no roads are set at 30 (assigned the corresponding resistance values according to the driving speeds). According to the resistance values set above, the vector layer of all types of roads in Guangdong can be converted into the raster layer and the size of one grid is $100 \mathrm{~m}$. We then used Matlab7.0 to merge all kinds of transport resistance layers, observing the principle that the resistance value of each grid is at a minimum. Finally, the grid layer with an 8-m spatial resolution of resistance values of road traffic in Guangdong can be determined.

The minimal cumulative resistance (MCR) model refers to a model that reflects the minimal cost of consumption required by a species in the process of moving from a source to a destination. The minimum cumulative resistance value reflects the potential possibility and tendency of species' movements and the connectivity and similarity between one unit with the source unit which can be judged through the size of a unit of minimum cumulative resistance (Zhang and Fan; 2012). The minimal cumulative resistance (MCR) model was first put forward by Knapen et al. (1992) and modified by Yu (1999).

$$
\mathrm{MCR}=f_{\min } \sum\left(D_{i j} \times R_{j}\right)
$$

where MCR is the minimum cumulative resistance value, $D_{i j}$ is the space distance overcome by a species from source $j$ to landscape unit $i$, and $R_{j}$ is the resistance coefficient of landscape unit $j$ to some kind of movement.

We inserted the dotted vector layer of cities, counties, towns, and the grid layer of road traffic resistance in Guangdong into the Cost Distance module of ArcGIS, then calculated the minimum cumulative resistance value of each grid to the destination in the province. Grids with small resistance values show intensive traffic accessibility to the destination.

\subsection{Data sources}

The vector-based data of rural settlement patches in 1990, 2000, and 2013 in Guangdong involved in this study comes from the cloud platform of geographical spatial data. In order to further improve this study's data accuracy, the second survey data of land in Guangdong in 2009 was used as a reference to carry out the supplementary vectorization of rural settlement patches on the basis of TM remote sensing image data in the corresponding year (based on the land use data of the whole domain of China which is interpreted by TM remote sensing data and images). Compared with the second land survey data, some information on the land types of rural residential areas has been lost. The basic data working layers of this study are the TM images in the original corresponding years. This study is based on the existing TM classified interpretation data of 1990, 2000, and 2013 and overlaps with the vector data from the second land survey of the related land types of rural residential areas in 2009 in the original image. Next, we conducted supplementary vectorization of the rural residential areas that are missing in the classified interpretation of TM images in the corresponding years according to the color and texture of the rural residential areas in the original TM remote sensing images. Since the precision of the second land survey data of 2009 is higher, the accuracy of the rural residential data extracted from the TM image data is improved through accurate and supplementary processing. Supplementary vectorization of the corresponding data based on the original TM remote sensing image data simultaneously ensures the consistency of data matching. The vector data of rural settlement patches in 1990, 2000, and 2013 used in the study are then acquired. The data on road traffic accessibility is acquired 
from the 2012 electronic map of China with a scale of 1:250,000 by converting the .TAB format of the MapInfo to the .shp format. The DEM and meteorological data used in this study comes from the Earth system science data sharing platform for geographical science and resources research of the Chinese Academy of Sciences.

\section{Results}

\subsection{Spatial distribution pattern and evolution of rural settlements in Guangdong}

Using the kernel density method to generate the density diagram of rural settlements in Guangdong province (Figure 1), the spatial differentiation of rural settlements in Guangdong province is conspicuous; the overall spatial distribution pattern is "dense in plains, sparse in mountainous areas." The present distribution of density cores of rural settlements is relatively decentralized, mainly forming two density cores in the Chaoshan plain east of Guangdong and the Zhanjiang plain platform west of Guangdong with a density range of $0.7-0.9 / \mathrm{km}^{2}$ (Figure 1c). The plain area of the Pearl River Delta has many concentrated secondary density core clusters of rural settlements with a density range of $0.5-0.6 / \mathrm{km}^{2}$. The density of rural settlements in the mountainous areas located to the north, west, and east of Guangdong is relatively sparse. In the province, the river network develops in the plains and low mountainous hilly areas; the terrain is relatively flat, and the cultivated land is rich in resources with an abundance of fishponds. The conditions for agricultural production are superior and the modern transportation is convenient, which are all advantageous to the development and growth of rural settlements. In the peripheral mountainous area of the Pearl River Delta, the altitude is high, the terrain complex, and the cultivated lands lack resources. The degree of traffic convenience is lower and the cultivated land resources are relatively fragmented, while rural settlements are distributed along the river surges and cultivated lands. Thus, a large quantity of small settlements has formed whose densities are all lower than $0.3 / \mathrm{km}^{2}$, which is far smaller than the density of the core regions. We carried out the map algebra calculation by using raster data of the kernel density of rural settlements in different years to determine the grid map of the rate of density fluctuations of rural settlements from 1900-2000, 2000-2013, and 1990-2013 (Figure 2), which reveals its characteristics of spatio-temporal variations. The density drop zones of rural settlements in Guangdong are mainly concentrated in the core region of the Pearl River Delta where the maximum density decrease of rural settlements is $0.15 \%$ per annum. The scale and scope of the disappearance of rural settlement patches from 2000 to 2013 is larger than that of 1990 to 2000; the fast development of the two developmental axes called Guang-Fo and Shen-Guan-Hui drives the rapid expansion of urban spaces. The integration of regional city networks in the Pearl River Delta has enhanced this even further. A large number of villages in the urban fringe have been integrated into towns and the land used for rural settlements have been converted into urban construction land on a large scale. Second, the disappearance of rural settlements in the surrounding area of prefecture-level cities and counties is also widespread, which has a significant impact on the extension of urban regional space driven by the urbanization process and the conversion of the settlement forms in rural geographical spaces. The average decreasing value of the density of rural settlements is between $0.05 \%$ and $0.10 \%$ per annum. At the same time, the size and number of rural settlements in the peripheral area of the Pearl 
River Delta still presents a tendency of growth and expansion which is mainly concentrated in the eastern, western, and northern parts of Guangdong where the maximum average increasing value of the kernel density of rural settlements reaches $0.45 \%$ per annum. Along with rapid urbanization, the land used for rural settlements in the peripheral area of the Pearl River Delta has been expanding continuously and the scale of the land used for rural settlements does not achieve the equilibrium of peg with a reduction of rural population outflow. From the field investigation it is clear that the phenomenon of rural hollowing out in the peripheral area of the Pearl River Delta is also widespread, while urban and rural household registration and the binary structure of land exert a profound impact on rural development and the evolution and development of rural settlements. The outflow of population elements in rural areas have been reduced, but the construction land for rural settlements continues to increase and expand.
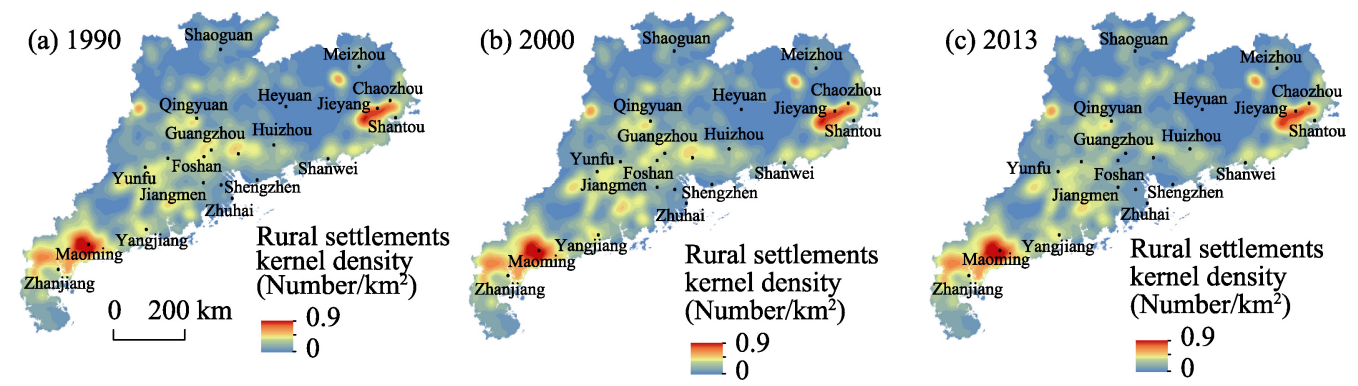

Figure 1 The spatial pattern of rural settlement kernel density in Guangdong Province from 1900 to 2013

(a) $1990-2000$

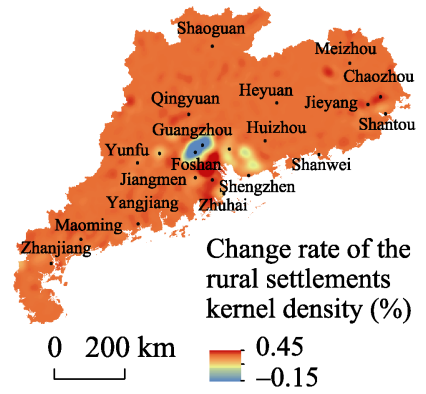

(b) 2000-2013

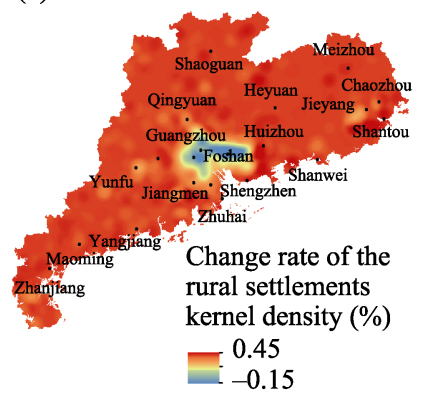

(c) $1990-2013$

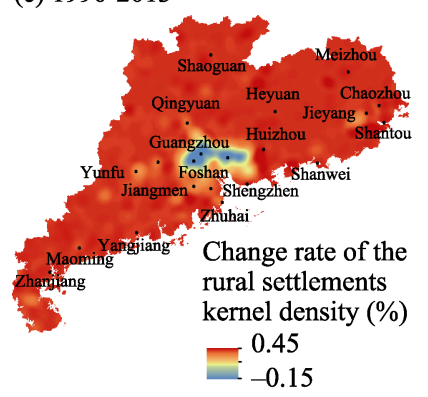

Figure 2 The change rate of the rural settlement kernel density in Guangdong Province from 1900 to 2013

\subsection{Statistical analysis of rural settlement space distribution based on road traffic accessibility}

Roads are the axes that form the connection between rural settlements and the main channel of material and information flows between settlements, as well as the foundation of rural association strength networks. Previous studies include the statistical analysis of the characteristics of the spatial distribution of rural settlements on the basis of the distance of adjacent traffic lines and the adjacent distance of neighboring towns. The spatial layout of rural settlements is affected by various locational conditions, and the accessibility of transportation integrating the influence of the adjacent distance of road traffic lines and the radiation effect of town centers forms the comprehensive measurement index of locational conditions. In this study, the different resistance values of road traffic are set according to different driving 
and walking speeds on the roads of different scale levels. In order to obtain the scales of the minimum cumulative accessible resistance value of each grid with a spatial resolution of 100 $\mathrm{m} \times 100 \mathrm{~m}$ for prefecture-level cities, counties (districts), villages, and towns, the Cost Distance analysis tools of GIS are used (Figure 3). By integrating the consideration of the levels of roads and the traffic accessibility of hierarchical roads in towns, it is possible to better represent the location conditions of each grid. To do so, we divide the minimum cumulative resistance value of traffic accessibility of $100 \mathrm{~m} \times 100 \mathrm{~m}$ grids for prefecture-level cities in Guangdong province into five zones as $<200,000,200,000-300,000,300,000-400,000$, $400,000-500,000,>500,000$ and so on; divide the minimum cumulative resistance value of traffic accessibility to the counties (districts) into five zones as $<100,000,100,000-150,000$, $150,000-200,000,200,000-250,000,>250,000$ and so on; and divide the minimum cumulative resistance value of traffic accessibility to villages and towns into five zones as $<45,000$, $45,000-90,000,90,000-135,000,135,000-180,000,>180,000$ and so on. We separately carried on the statistics of the number and size of the spatial distribution of rural settlements within each zone (Table 1). The number of rural settlement patches in the area where the minimum cumulative resistance values to prefecture-level cities are under 400,000 is 353,919 , accounting for $71.27 \%$ of the total number and $80.5 \%$ of the total area of rural settlements. The number of rural settlement patches in the area where the minimum cumulative resistance value to the countries is under 200,000 is 425,797 , accounting for $85.72 \%$ of the total number and $90.36 \%$ of the total area of rural settlements. The number of rural settlement patches in the area where the minimum cumulative resistance values to the villages and towns are under 200,000 is 479,661 , accounting for $96.32 \%$ of the total number and $96.86 \%$ of the total area. The low value directivity characteristics for the minimum cumulative resistance of road traffic accessibility of the spatial distribution of rural settlements in Guangdong are significant. The neighbor correlation between the spatial distribution of rural settlements and traffic accessibility to central towns at different levels varies, and the accessibility of the roads to villages and towns has the greatest influence on the spatial distribution of rural settlements. However, the influence on the spatial distribution of rural settlements of the accessibility of the roads to the level of prefecture-level cities is relatively smaller.
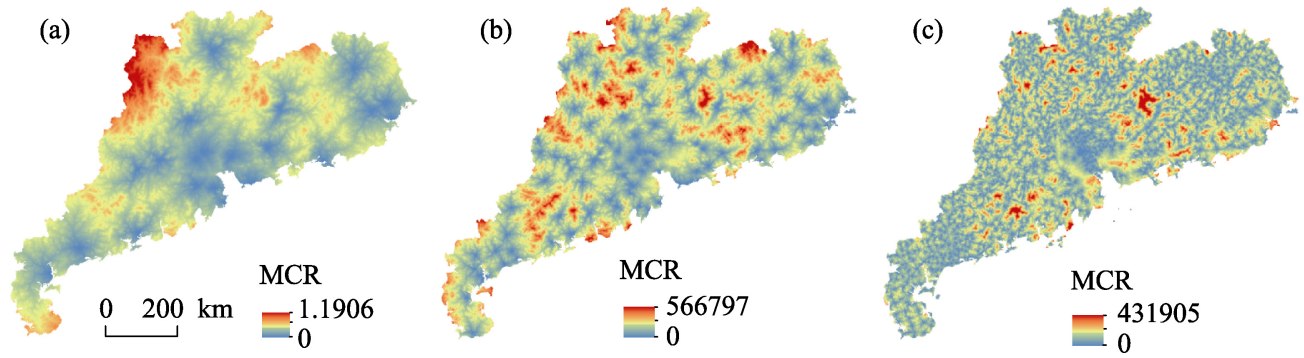

Figure 3 The spatial distribution of road traffic accessibility resistance values to prefecture-level cities (a), counties (b), and towns (c) in Guangdong Province in 2012

\subsection{Statistical analysis of the spatial distribution of rural settlements based on the physical geographical main control elements}

Physical geographical factors are the basis for the formation and development of rural settlements, and terrain is the dominant factor that provides space for the formation and develop- 
ment of rural settlements, while restricting the spatial layout of rural settlements. Elevation and slope are the two important factors influencing the spatial pattern of rural settlements. The main influencing factors of rural settlements mainly include elevation, slope, average annual precipitation, average annual temperature, and distance to the main rivers (Figure 4). We divided the elevation of Guangdong into five altitudinal belts as $<100 \mathrm{~m}, 100-300 \mathrm{~m}$, $300-500 \mathrm{~m}, 500-700 \mathrm{~m},>700 \mathrm{~m}$ and five slope scopes as $<5^{\circ}, 5^{\circ}-10^{\circ}, 10^{\circ}-15^{\circ}, 15^{\circ}-25^{\circ}$, $>25^{\circ}$, and carried out statistical survey of the scale of rural settlements within the scope of

Table 1 Rural settlements in different zones of road traffic accessibility resistance values to prefecture-level cities, counties, and towns in Guangdong Province in 2013

\begin{tabular}{|c|c|c|c|c|c|c|c|c|c|}
\hline $\begin{array}{c}\text { Resistance } \\
\text { value to } \\
\text { prefec- } \\
\text { ture-level } \\
\text { cities }\left(\times 10^{4}\right)\end{array}$ & Number & $\begin{array}{c}\text { Percentage } \\
(\%)\end{array}$ & $\begin{array}{l}\text { Area } \\
\text { (ha) }\end{array}$ & $\begin{array}{l}\text { Percentage } \\
(\%)\end{array}$ & $\begin{array}{l}\text { Resistance } \\
\text { value to } \\
\text { counties } \\
\left(\times 10^{4}\right)\end{array}$ & Number & $\begin{array}{l}\text { Percentage } \\
(\%)\end{array}$ & $\begin{array}{l}\text { Area } \\
\text { (ha) }\end{array}$ & $\begin{array}{c}\text { Percentage } \\
(\%)\end{array}$ \\
\hline$<20$ & 123183 & 24.81 & 282599.8 & 39.46 & $<10$ & 153337 & 30.87 & 315588.46 & 44.06 \\
\hline $20-30$ & 124256 & 25.02 & 165219.2 & 23.07 & $10-15$ & 162224 & 32.66 & 215535.62 & 30.09 \\
\hline $30-40$ & 106480 & 21.44 & 128698.7 & 17.97 & $15-20$ & 110236 & 22.19 & 116102.82 & 16.21 \\
\hline $40-50$ & 80260 & 16.16 & 72256.98 & 10.09 & $20-25$ & 56121 & 11.30 & 54703.57 & 7.64 \\
\hline$>50$ & 62419 & 12.57 & 67383.22 & 9.41 & $>25$ & 14863 & 2.99 & 14355.27 & 2.00 \\
\hline \multicolumn{2}{|c|}{$\begin{array}{l}\text { Resistance value } \\
\text { to towns }\left(\times 10^{4}\right)\end{array}$} & Number & \multicolumn{2}{|c|}{ Percentage $(\%)$} & \multicolumn{3}{|c|}{ Area (ha) } & \multicolumn{2}{|c|}{ Percentage (\%) } \\
\hline \multicolumn{2}{|l|}{$<4.5$} & 236972 & \multicolumn{2}{|c|}{47.58} & \multicolumn{3}{|c|}{342533.842} & \multicolumn{2}{|l|}{47.62} \\
\hline \multicolumn{2}{|l|}{$4.5-9.0$} & 183301 & \multicolumn{2}{|c|}{36.81} & \multicolumn{3}{|c|}{267395.335} & \multicolumn{2}{|l|}{37.18} \\
\hline \multicolumn{2}{|c|}{$9.0-13.5$} & 59388 & \multicolumn{2}{|c|}{11.93} & \multicolumn{3}{|c|}{86747.7314} & \multicolumn{2}{|l|}{12.06} \\
\hline \multicolumn{2}{|c|}{$13.5-18.0$} & 14326 & \multicolumn{2}{|c|}{2.88} & \multicolumn{3}{|c|}{17894.74635} & \multicolumn{2}{|l|}{2.49} \\
\hline \multicolumn{2}{|l|}{$>18.0$} & 4013 & \multicolumn{2}{|c|}{0.81} & \multicolumn{3}{|c|}{4669.517706} & \multicolumn{2}{|l|}{0.65} \\
\hline
\end{tabular}

(a) Elevation

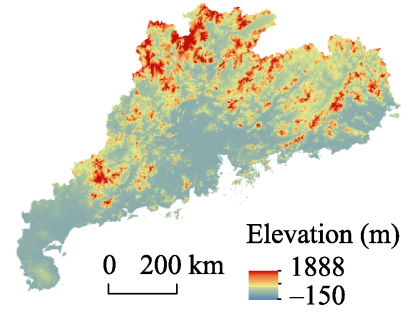

(d) Annual precipitation

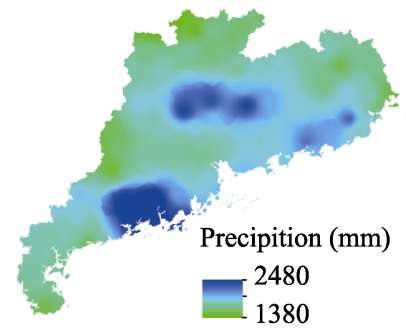

(b) Slope

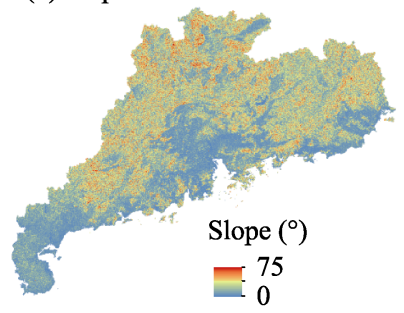

(c) Distance to the main rivers

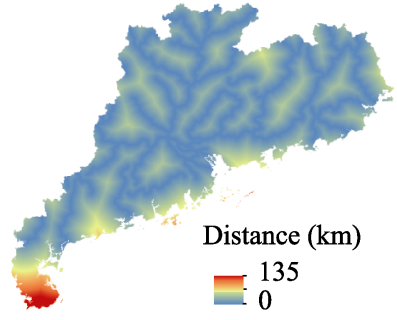

(e) Annual average temperature

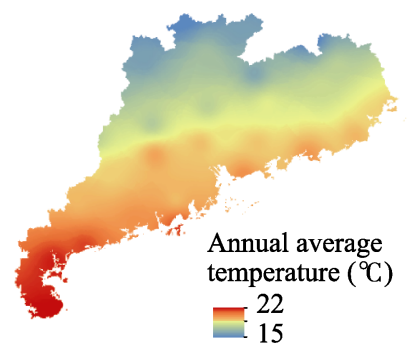

Figure 4 The spatial patterns of the major physical geographical factors in Guangdong Province 
different altitudes and slopes (Table 2). The rural settlement patches in Guangdong are mainly distributed in areas where the altitude height is below $100 \mathrm{~m}$. The total number of rural settlement patches is 279,634 , accounting for $55.99 \%$ of the total number and $77.74 \%$ of the total area. Within the altitudinal range of 100-300 m, the number of rural settlements patches is 167,842 , accounting for $33.61 \%$ of the total number and $17.99 \%$ of the total area of rural settlements. Compared to the first elevation belt, the number of rural settlement patches decreases gradually. The area of rural settlements located in the area with an altitude above $500 \mathrm{~m}$ accounts for less than $5 \%$ of the total area. The number of rural settlements distributed on slopes with a gradient range of $0^{\circ}-10^{\circ}$ is 340,260 , accounting for $82.51 \%$ of the total area. The number of rural settlements distributed on slopes with a gradient of over $10^{\circ}$ only accounts for $17.49 \%$ of the total area of rural settlements. The distribution of rural settlements in Guangdong province shows that rural settlements decline with the rise of elevation and gradient.

Table 2 Rural settlements in different zones of elevation and slope in Guangdong Province in 2013

\begin{tabular}{cccccccccc}
\hline $\begin{array}{c}\text { Elevation } \\
(\mathrm{m})\end{array}$ & Number & $\begin{array}{c}\text { Percentage } \\
(\%)\end{array}$ & Area (ha) & $\begin{array}{c}\text { Percentage } \\
(\%)\end{array}$ & $\begin{array}{c}\text { Slope } \\
(\%)\end{array}$ & Number & $\begin{array}{c}\text { Percentage } \\
(\%)\end{array}$ & Area (ha) & $\begin{array}{c}\text { Percentage } \\
(\%)\end{array}$ \\
\hline$<100$ & 279634 & 55.99 & 562847.5 & 77.74 & $<5$ & 194421 & 38.93 & 382235.6 & 52.82 \\
$100-300$ & 167842 & 33.61 & 130262.92 & 17.99 & $5-10$ & 145839 & 29.2 & 214827.7 & 29.69 \\
$300-500$ & 38177 & 7.64 & 22833.94 & 3.15 & $10-15$ & 75585 & 15.14 & 73520.49 & 10.16 \\
$500-700$ & 11064 & 2.22 & 6315.56 & 0.87 & $15-25$ & 65703 & 13.16 & 43263.33 & 5.98 \\
$>700$ & 2707 & 0.54 & 1396.14 & 0.19 & $>25$ & 17852 & 3.57 & 9801.06 & 1.35 \\
\hline
\end{tabular}

The Lingnan area is rich in precipitation and its river networks are widespread. The functional characteristic of the agricultural production of rural settlements determines the features of the spatial distribution of rural settlements through which the river system has the characteristics of the Lingnan area flows. The characteristics of agricultural valley civilizations are obvious, and the hydrothermal condition is the basic physical geographical factor of agricultural production which is also an important index to evaluate the suitability of human settlement. Based on the ArcGIS software platform, the spatial analysis of distance distribution according to the vector data of the main rivers in Guangdong is calculated. The adjacent distance to the main rivers in the province can be divided into five adjacent zones as $<10 \mathrm{~km}, 10-20 \mathrm{~km}, 20-30 \mathrm{~km}, 30-40 \mathrm{~km}$, and $>40 \mathrm{~km}$. The multi-year average temperatures are divided into five scopes as $<16^{\circ} \mathrm{C}, 16-17^{\circ} \mathrm{C}, 17-18^{\circ} \mathrm{C}, 18-19^{\circ} \mathrm{C}$, and $>19^{\circ} \mathrm{C}$. Statistics are collected on the number and proportion of the spatial distribution of rural settlements (Table 3). The number of rural settlements that are distributed within the scope of less than $20 \mathrm{~km}$ away from the main rivers is 411,374 , accounting for $82.58 \%$ of the total number, while the number of rural settlements that exceed the scope of $30 \mathrm{~km}$ is 14,072 , only accounting for $2.82 \%$ of the total percentage. A large proportion of Guangdong belongs to a tropical climate where the average annual temperature is generally high and the spatial variation of temperature is mainly due to factors of latitude and vertical zonality. It can be seen from the statistical results that $75.41 \%$ of rural settlements are located in areas where the multi-year average temperature is above $18^{\circ} \mathrm{C}$; these areas happen to be in the plain area of the Pearl River Delta. However, the regions where the multi-year average temperature is a bit lower are principally concentrated in the mountainous areas on the periphery of the Pearl River Delta. Multiple constraints such as terrain factors and the convenient levels of traffic, 
as well as the agricultural production resources, lead to the discrete spatial distribution and small scale of rural settlements, which is consistent with the results of terrain statistical analysis.

Table 3 Rural settlements in different zones of the distance from main rivers and temperature in Guangdong Province in 2013

\begin{tabular}{cccccccccc}
\hline $\begin{array}{c}\text { Distance } \\
(\mathrm{km})\end{array}$ & Number & $\begin{array}{c}\text { Percentage } \\
(\%)\end{array}$ & $\begin{array}{c}\text { Area } \\
(\mathrm{ha})\end{array}$ & $\begin{array}{c}\text { Percentage } \\
(\%)\end{array}$ & $\begin{array}{c}\text { Annual aver- } \\
\text { age tempera- } \\
\text { ture }\left({ }^{\circ} \mathrm{C}\right)\end{array}$ & Number & $\begin{array}{c}\text { Percentage } \\
(\%)\end{array}$ & $\begin{array}{c}\text { Area (ha) } \\
(\%)\end{array}$ & $\begin{array}{c}\text { Percentage } \\
(\%)\end{array}$ \\
\hline$<10$ & 262033 & 52.60 & 386671.2 & 53.40489 & $<16$ & 4637 & 0.93 & 3337.59 & 0.47 \\
$10-20$ & 149341 & 29.98 & 179346.4 & 24.77033 & $16-17$ & 49352 & 9.92 & 46745.21 & 6.51 \\
$20-30$ & 72714 & 14.60 & 107934.2 & 14.90727 & $17-18$ & 152311 & 30.62 & 126434.36 & 17.62 \\
$30-40$ & 8093 & 1.62 & 20802.5 & 2.873127 & $18-19$ & 175543 & 35.29 & 286322.48 & 39.90 \\
$>40$ & 5979 & 1.20 & 24857.18 & 3.433137 & $>19$ & 115614 & 23.24 & 254841.83 & 35.51 \\
\hline
\end{tabular}

\subsection{Quantitative identification of the multi-factors affecting the spatial distribution of rural settlements}

The space distribution and dynamic changes of rural settlements are doubly affected by the original conditions of physical geographical elements and socio-economic development (Yang et al., 2015). We can gain further quantitative identification of the influencing factors and the influence degrees of the spatial distribution of rural settlements on the basis of the statistics of the characteristics of the spatial distribution of rural settlements. This is based on traffic accessibility and the grading and internal classification of typical physical geographical factors. Due to the restriction of data availability, this study mainly focuses on the physical geographical elements and traffic accessibility factors of the spatial distribution of rural settlements. Eight factors were selected as elevation $\left(x_{1}\right)$, gradient $\left(x_{2}\right)$, multi-year average precipitation $\left(x_{3}\right)$, the distance from the main rivers $\left(x_{4}\right)$, multi-year average temperature $\left(x_{5}\right)$, the minimum cumulative resistance value of the accessibility to prefecture-level cities $\left(x_{6}\right)$, the minimum cumulative resistance value of the accessibility to counties (districts) $\left(x_{7}\right)$, the minimum cumulative resistance value of the accessibility to villages and towns $\left(x_{8}\right)$, and so on. During the establishment of the regression model, the data normalization of the standard deviation of the eight factors was carried on respectively.

Due to the multilevel road traffic data at the end of 2012, in this study we selected the essential data established by the data model of the distribution of rural settlements in 2013 in Guangdong. We converted the vector data of rural settlement patches in 2013 in Guangdong to a 01 binary raster data layer with a spatial resolution of $100 \mathrm{~m}$. By extracting the binary raster data and raster data of eight factors of rural settlements corresponding to the sampling point location by means of random sampling (the number of sampling points is 12000), the Logistic $^{1}$ regression model between the spatial distribution of rural settlements in Guangdong and the influencing factors was established as follows:

$$
\log \left(\frac{P}{1-P}\right)=-0.324 x_{1}-0.273 x_{2}-0.041 x_{3}-0.038 x_{4}-0.135 x_{8}-1.108
$$

Since the regression coefficients of $x_{5}, x_{6}$, and $x_{7}$ did not pass the significance testing of

\footnotetext{
${ }^{1}$ Logistic regression models can deal with the binary data regression primal. In this model, $\mathrm{P}$ is on behalf of the appearance probability of the spatial distribution of rural settlements.
} 
0.05 in the process of model establishment, they were eliminated from the model. The test value of ROC is 0.82 , as shown in the results of the Logistic regression. The spatial distribution of rural settlements in Guangdong has a spatial distribution directivity of low altitude, low slope, adjacent rivers, as well as to villages and towns. The formation and development, shape and size, and space layout of rural settlements are influenced by natural conditions, socio-economic conditions, historical developments, and habits and customs, so the pattern of the spatial distribution of rural settlements is a comprehensive outcome of multiple factors. The development and spatial layout of rural settlements has historical continuity. Natural conditions are the foundation of rural settlements and the climate and terrain conditions have a significant influence on the distribution of rural settlements. It can be seen from the regression results that the altitude, gradient, multi-year average precipitation, distance from the main rivers, and minimum cumulative resistance value of the accessibility to villages and towns all present a negative correlation with the distribution of rural settlements. The regression coefficients are $0.324,0.273,0.324,0.038$, and 0.135 respectively. Natural factors are the basis of the formation and development of the spatial structures of rural settlements. The Pearl River Delta plain, the Chaoshan plain of Hanjiang River Delta, and the hilly tableland region of Zhanjiang are areas generally suitable for rural settlements in the traditional agricultural production period due to the flat terrain, intertwined river networks, abundant cultivated land resources, convenient transportation, suitable production and living conditions. The distribution of rural settlements in such areas is quite dense, and the rural scale is relatively larger. Water is one of the basic conditions for the formation of settlements. The formation and development of rural settlements has a close and inseparable relationship with water resources. Surface and underground water resources have a direct impact on the form, evolution, and spatial distribution of rural settlements. The spatial distribution of settlements has obvious water source directivity. It is also doubly influenced by the spatial dispersion and accessibility of cultivated land resources. The characteristic of the spatial layout in the beaded style of rural settlements that lie near the river valleys and traffic lines in the peripheral mountainous areas of the Pearl River Delta region is obvious. The formation and development of rural settlements has a close relationship with socio-economic development. In the process of modernization, the construction of traffic infrastructure and the improvement of regional accessibility levels play a crucial role in the spatial extension of rural settlements and the land use changes of rural residential areas. The development of transportation promotes the spatial extension of rural settlements and changes the external form of villages, and is also the basic support power of the spatial extension of modern countries. The developmental level of traffic and the direction and levels of transport lines affect the pattern evolution of rural settlements. The improvement of means of transportation and the construction of traffic networks and infrastructure affects the transformation of the form, distribution, and the spatial pattern of the surrounding rural settlements. The location advantages such as modern and efficient traffic conditions and proximity to markets boost space expansion and increase the number of rural settlements.

The spatial evolution and development of rural settlements are comprehensively affected by multi-dimensional elements. The physical geographical element is the basic support driving force that establishes the fundamental historic pattern of the spatial distribution of rural settlements. It is also the basis of the formation and development of settlement envi- 
ronments, and the basic constitution of physical geographical factors. Factors such as topography, landforms, hydrothermal conditions, cultivated land resource endowment, and so on are the basic supports of the regional production and life functions of rural settlements and have a fundamental influence on the spatial dynamics and evolution of rural settlements. The spatial organization of extensive rural areas relies on the village and town systems, where villages and towns are central places within the region and support the functions of markets, science and education, culture and health, consumption, and public services. This exerts a significant influence on rural socio-economic development which in turn affects the spatial evolution and development of rural settlements. From the perspective of the central radiation of regional cities, villages, and towns, the central radiation of villages and towns has a significant influence on the spatial distribution of rural settlements. However, compared to the villages and towns, the radiation effect of central places with high levels, such as prefecture-level cities and counties (districts), on the spatial distribution of rural settlements is insignificant. The construction of the village and town systems and matching service facilities is the core of the stationing planning of villages and towns. Strengthening the traffic accessibility of rural settlements to villages and towns is the foundation of the construction of village and town systems, and also an important link in guiding the spatial reconstruction integration of rural settlements.

\section{Discussion on the research content framework of the evolution mecha- nism of rural settlements}

Rapid urbanization and industrialization has brought about the swift transformation of urban and rural regional systems. The scale and speed of the exchange flow of production factors between rural and urban areas has increased, production factors and intellectual resources in rural areas precede that of non-agricultural transformation, and rural regional spaces are facing transformational development. Rural material, social, cultural, and ecological spaces are undergoing a process of transformation and reconstruction. The spatial distribution and influencing factors of rural settlement systems under the traditional and modern artistic conception has drawn wide attention in educational circles, with scholars mostly focusing on revealing spatial distribution patterns and the spatial directivity characteristics of geographical elements of rural settlements, etc. However, against the macro background of globalization, information, and urbanization, the spatial evolution and layout optimization of rural settlements is affected by multiple internal and external factors, especially since globalization and information have significant effects on the reconstruction of rural spaces, and multiple driving forces promote the diversified changes of rural regional spaces. Based on this, we attempt to discuss the future research content framework of the spatial distribution, evolution, and reconstruction mechanisms of rural settlements against the background of the diversified differentiation of rural regional space (Figure 5). At present, a large number of empirical case studies have demonstrated that the distribution of rural settlements has a regular pattern of space directivity. On this basis, we focus on the evolution analysis of the spatial structure of rural settlements and the landscape of the type of settlements that deepen the spatial process and the evolution of the form and pattern of rural settlements, and explore the mechanism and path of the reconstruction of material space and the resource optimization allocation of rural settlements. In the new period, rapid urbanization leads to the mas- 
sive outflow of the rural labor force which aggravates the occurrence of the collapse or "hollowing out" of rural material spaces and rural societies, leading to the idle waste of resources and the decline of the landscape of rural settlements. The socio-cultural spaces in rural areas transform quietly, a transformation that is embodied in series of changes such as neighborhood relations, social networks, clan kinship, and the differentiation of residential space and social capitalization. Theoretical research on rural social space reconstruction is insufficient; this study will be an important element of future rural geography studies and will enrich and promote the study of the socio-cultural shift in Chinese rural geography. In research on landscape transformation in rural areas, the study of the type of rural settlements, land-use structures, architectural styles, the miscellaneous property of settlements, and the evolution and restrictions of the eco-environment is in need of a multidisciplinary, comprehensive integration and intersection study based on rural geography, architecture, ecology, and so on, which is vital to the enrichment of the research content of rural geography.

Current studies on the spatial dynamics of rural settlements are relatively common, and the rural geographical research on the aspects of the micro landscape forms of rural settlements and the spatial construction of traditional settlements, as well as rural social networks, social individual behavior, group behavior, social autonomy, and the reconstruction of socio-cultural spaces have the potential for significant academic theoretical contributions. This paper applies the quantitative identification of the spatial distribution of rural settlements and its main controlling factors. This content framework for future research is summed up in order to further deepen research with different scales of "micro-meso-macro" on the reconstruction of rural multi-dimensional space in the Pearl River Delta and its peripheral areas, as well as to reveal the characteristics, processes, patterns, and mechanisms of the reconstruction and transformation of rural spaces in different regions. Docking in rural planning practice, generally the logic of rural stationing planning is the construction of a central place and the improvement of a network system. The study found that the radiation effect of villages and towns to the spatial pattern and the development of countries is significant, which shows that the construction of a life service circle in which villages and towns act as the core is particularly important to the spatial optimization allocation of rural land resources, the strengthening of the protection of socio-cultural space traditions, and the reconstruction of production, living, and ecological spaces in rural areas. In the era of Internet + , the rural production and consumption market network has been reconstructed. The topics such as the theory and mode of the participation of Chinese rural development in globalization will be the focus of the field, whose research on rural reconstruction in China will be deepened. Affected by the global economic crisis and the transformation of domestic industries, the partial migrant labor force in rural areas presents a weak trend of reflux. The return of the labor force will greatly influence rural settlement spaces and the socio-economic development and reconstruction. This new phenomenon will also be one of the research fields on which the study of rural geography will focus emphatically. In addition, cities in metropolitan areas have been continually expanding. The urban disease appears gradually, in the periphery of metropolitan areas, and is likely to generate a counter urbanization process. The interface docking of urbanization and rurality and the exclusion and integration of the construction of social networks will be important fields in need of further research. We will continue to focus on and subsequently conduct a related series of research in the future. 
research in the future.

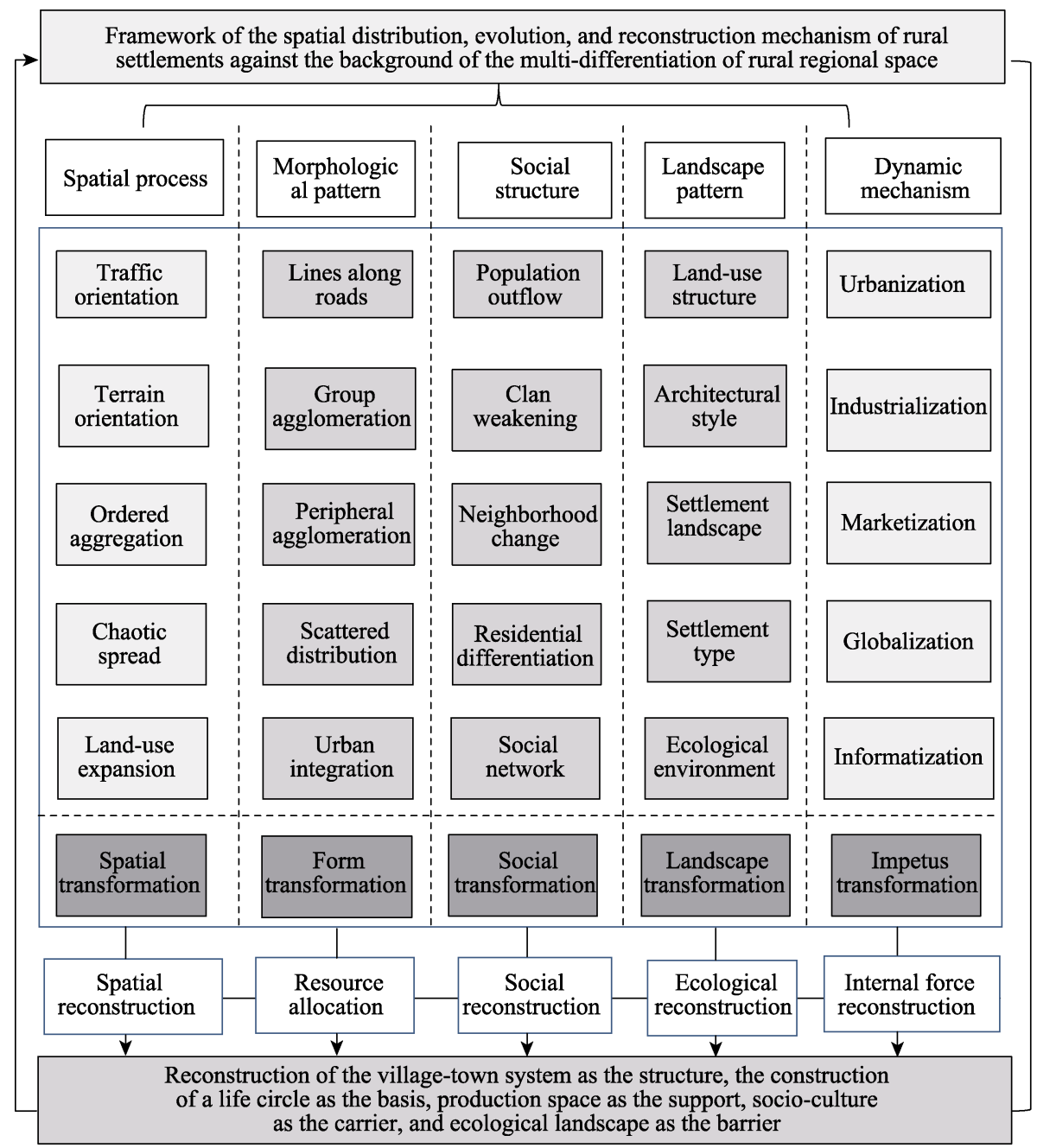

Figure 5 The research framework of rural settlements' spatial distribution, evolution, and reconstruction against the background of rural spatial diversity transformation in China

\section{Conclusions}

(1) In terms of the density distribution, the spatial difference of rural settlements in Guangdong province is generally significant; the spatial distribution of rural settlements in Guangdong has a significant spatial distribution directivity of low altitude, low slope, adjacent to rivers, as well as to villages and towns. The overall spatial distribution pattern is "Dense in plains, while sparse in mountainous areas." The present distribution of density cores of rural settlements is relatively decentralized, mainly forming two density cores in the form of the Chaoshan plain to the east and the Zhanjiang plain platform to the west of Guangdong. These are both suitable areas for widely distributing rural settlements in the traditional agricultural production period due to the flat terrain, intertwined river networks, and abundant cultivated land resources. The characteristics of the spatial layout in the beaded style of rural settlements that are near the river valleys and traffic lines in the moun- 
tainous areas on the periphery of the Pearl River Delta region is obvious. It is also influenced doubly by the spatial dispersion of cultivated land resources and accessibility.

(2) Elevation and slope are the two important topographic factors influencing the spatial pattern of rural settlements and have a significant influence on the scale, form, and distribution of rural settlements. The rural settlement patches in Guangdong are mainly distributed in areas where the altitude heights are below $100 \mathrm{~m}$, accounting for $55.99 \%$ of the total number and $77.74 \%$ of the total area. Within the altitudinal range of 100-300 $\mathrm{m}$, the number of rural settlement patches account for $33.61 \%$ of the total number and $17.99 \%$ of the total area. Rural settlements located in areas with an altitude above $500 \mathrm{~m}$ account for less than $5 \%$ of the total. The number of rural settlements distributed on the slope with a gradient range of $0^{\circ}-10^{\circ}$ is 340,260 , accounting for $82.51 \%$ of the total area.

(3) The value of the minimum cumulative resistance of traffic accessibility of multilevel roads to central-place cities (towns) has a significant influence on rural settlements' spaces, showing a significant negative correlation. Traffic accessibility of multilevel roads to villages and towns has the greatest influence on the spatial distribution of rural settlements. The central radiation effect of villages and towns plays an important role in the construction of village and town systems. The effect of traffic accessibility of multilevel roads to the counties (districts) on rural settlements is not particularly evident. As natural waterways, rivers have an important influence on the development and growth of traditional villages. Temperature and precipitation exert some influence on the spatial distribution of rural settlements, the heterogeneity of elements is comparatively small in the tropical regions, and its effects are associated with the influence of physical geographical factors such as terrain on the spatial distribution and evolution of rural settlements.

(4) Docking in the time-background of urbanization, information, and globalization, research on rural geography should focus on the core problems such as the micro landscape forms of rural settlements and the spatial construction of traditional settlements, as well as the rural social network, social individual behavior, group behavior, social autonomy, and the constant reconstruction of socio-cultural space. In the era of Internet+, core topics such as the reconstruction mechanism of rural production and consumption market networks as well as integration into globalization will be key fields in need of further research. In the discipline of the construction of urban-rural planning and rural planning practice, constructing life and service circles in rural areas in which villages and towns act as the core, reconstructing and optimizing the village and town systems, perfecting the diversification of production in villages and towns and the functions of consumption and public services, as well as the theory and practice of planning, construction, and production, life, ecological, historical, and cultural spaces will be momentous research fields and directions that urgently demand that we deepen our understanding of urban-rural planning.

\section{References}

Arthur G, Judith G, 1966. Christaller's Central Place Theory. Journal of Geography, 65(5): 220-226.

Chen C, Gao J L, Chen J L, 2017. Institutional changes, land use dynamics, and the transition of rural settlements in suburban China: A case study of Huishan District in Wuxi city. Habitat International, 70: 24-33.

Fan S Y, 1994. The evolution mechanism \& study contents on the spatial structure about rural settlement. Journal of Northwest University (Natural Science Edition), 24(4): 295-304. (in Chinese) 
Guo X D, Ma L B, Zhang Q Y, 2013. The spatial distribution characteristics and the basic types of rural settlement in loess hilly area: Taking Qin'an County of Gansu Province as a case. Scientia Geographica Sinica, 33(1): 45-51. (in Chinese)

Hai B B, Li X J, Xu J W, 2013. Spatio-temporal evolution of rural settlements in Gongyi. Geographical Research, 32(12): 2257-2269. (in Chinese)

Hamerow H, 2012. Rural Settlements and Society in Anglo-Saxon England. London: Oxford University Press.

He R W, Chen G J, Liu S Q et al., 2012. Research progress and tendency of Chinese rural settlements geography. Progress in Geography, 31(8): 1055-1062. (in Chinese)

Huang X Y, Cao X S, Li T, 2011. The relationship between regional transport superiority and regional economic performance in Hainan. Geographical Research, 30(6): 985-999. (in Chinese)

Janečková Molnárová K, Skřivanová Z, Kalivoda O et al., 2017. Rural identity and landscape aesthetics in exurbia: Some issues to resolve from a Central European perspective. Moravian Geographical Reports, 25(1): $2-12$.

Knappen J P, Scheffer M, Harms B, 1992. Estimating habitat isolation in landscape planning. Landscape and Urban Planning, 23(1): 1-16.

Li H B, Zhang X L, 2012. A review and trend on rural settlement geography abroad. Human Geography, 27(4): 103-108. (in Chinese)

Li Q L, Ma X D, Shen Yi, 2012. Analysis of spatial pattern of rural settlement in northern Jiangsu. Geographical Research, 31(1): 144-154. (in Chinese)

Liu X F, Shu J M, Zhang L B, 2010. Research on applying minimal cumulative resistance model in urban land ecological suitability assessment: As an example of Xiamen City. Acta Ecologica Sinica, 30(2): 421-428. (in Chinese)

Liu Y S, Yang Y Y, Li Y R, et al., 2017. Conversion from rural settlements and arable land under rapid urbanization in Beijing during 1985-2010. Journal of Rural Studies, 51: 141-150.

Long H L, 2013. Land consolidation and rural spatial restructuring. Acta Geographica Sinica, 68(8): 1019-1028. (in Chinese)

Long H L, Liu Y S, Wu X Q et al., 2009. Spatio-temporal dynamic patterns of farmland and rural settlements in $\mathrm{Su}-\mathrm{Xi}-\mathrm{Chang}$ region: Implications for building a new countryside in coastal China. Land Use Policy, 26(2): $322-333$.

Ma L B, Guo X D, Zhang Q Y, 2012. Spatio-temporal distribution and optimization of rural settlements in Gangu county of loess hilly area. Transactions of the Chinese Society of Agricultural Engineering, 28(13): 217-225. (in Chinese)

Ma X D, Li Q L, Shen Y, 2012. Morphological difference and regional types of rural settlements in Jiangsu Province. Acta Geographica Sinica, 67(4): 516-525. (in Chinese)

Peng Y, 2015. A comparison of two approaches to develop concentrated rural settlements after the 5.12 Sichuan Earthquake in China. Habitat International, 49: 230-242.

Quinn B, Wilks L, 2017. Festival heterotopias: Spatial and temporal transformations in two small-scale settlements. Journal of Rural Studies, 53: 35-44.

Ren P, Hong B T, Liu Y et al., 2014. A study of spatial evolution characteristics of rural settlements and influences of landscape patterns on their distribution using GIS and RS. Acta Ecologica Sinica, 34(12): 3331-3340. (in Chinese)

Schwarz K, 2015. Censer fragmentation and life history: Rural domestic settlement enchainment and accumulation activities and the Classic-Postclassic transition of the Petén Lakes region, Guatemala. Geophysical Research Letters, 33(1): 89-90.

Tang C L, He Y H, Zhou G H et al., 2014. The research on optimization mode of spatial organization of rural settlements oriented by life quality. Acta Geographica Sinica, 69(10): 1459-1472. (in Chinese)

Tian G J, Qiao Z, Gao X L, 2014. Rural settlement land dynamic modes and policy implications in Beijing metropolitan region, China. Habitat International, 44: 237-246.

Tian Y, Kong X, Liu Y et al., 2016. Restructuring rural settlements based on an analysis of inter-village social 
connections: A case in Hubei Province, Central China. Habitat International, 57: 121-131.

Trukhachev A, 2015. Methodology for evaluating the rural tourism potentials: A tool to ensure sustainable development of rural settlements. Sustainability, 7(3): 3052-3070.

Wang C, Fei Z H, Ye Q L et al., 2014. Rural settlement space reconstruction strategy and implementation based on symbiosis theory on village scale. Transactions of the Chinese Society of Agricultural Engineering, 30(3): 205-214. (in Chinese)

Woods M, 2007. Engaging the global countryside: Globalization, hybridity and the reconstitution of rural place. Progress in Human Geography, 31(4): 485-507.

Xi J, Wang X, Kong Q et al., 2015. Spatial morphology evolution of rural settlements induced by tourism. Journal of Geographical Sciences, 25(4): 497-511.

Yang R, Liu Y S, Long H L et al., 2015a. Spatio-temporal characteristics of rural settlements and land use in the Bohai Rim of China. Journal of Geographical Sciences, 25(5): 559-572.

Yang R, Liu Y S, Long H L et al., 2015b. Research progress and prospect of rural transformation and reconstruction in China: paradigms and main content. Progress in Geography, 34(8): 1019-1030. (in Chinese)

Yang R, Liu Y S, Long H L et al., 2015c. Spatial-temporal characteristics of rural residential land use change and spatial directivity identification based on grid in the Bohai Rim in China. Geographical Research, 34(6): 1077-1087. (in Chinese)

Yang R, 2016. Spatial coupling cooperative analysis of road transport superiority and urbanization at county level in China. Progress in Geography, 35(7): 806-815. (in Chinese)

Yang R, Xu Q, Long H L, 2016. Spatial distribution characteristics and optimized reconstruction analysis of China's rural settlements during the process of rapid urbanization. Journal of Rural Studies, 47: 413-424.

Yin H T, Chen Z X, 1995. Spatial distribution and evolution of the rural settlements in Shaanxi. Human Geography, 10(4): 17-24. (in Chinese)

Yu K J, 1999. Landscape ecological security patterns in biological conservation. Acta Ecologica Sinica, 19(1): 8-15. (in Chinese)

Zeng S S, Zhou G H, Xiao G Z et al., 2011. A review of rural settlements from the perspective of geography. Human Geography, 26(2): 68-73. (in Chinese)

Zeng Z Z, Fang X Q, Ye Y, 2011. The process of land cultivation based on settlement names in Jilin Province in the past 300 years. Acta Geographica Sinica, 66(7): 985-993. (in Chinese)

Zhang Y K, Fan J, 2012. Research on growth limit of urban space based on the stability of ecosystem: A case study of Beijing. Economic Geography, 32(6): 53-58. (in Chinese)

Zhou G H, He Y H, Tang C L et al., 2011. Dynamic mechanism and present situation of rural settlements evolution in China. Acta Geographica Sinica, 66(4): 515-524. (in Chinese)

Zhou G H, He Y H, Tang C L et al., 2013. Dynamic mechanism and present situation of rural settlement evolution in China. Journal of Geographical Sciences, 23(3): 513-524. 